\title{
A Case of Heel Reconstruction with a Reverse Sural Artery Flap in a Hemophilia B Patient
}

\author{
Byung Kwon Lee, Jeong Su Shim \\ Department of Plastic and Reconstructive Surgery, Catholic University of Daegu School of Medicine, Daegu, Korea
}

Hemophilia B is a rare blood coagulation disorder. Complications such as bleeding and hematoma can cause necrosis of flaps, wound disruption, and the disturbance of wound healing. In particular, guidelines for flap operations in hemophilia B patients have still not been defined, and case reports are rare. We reconstructed the heel of a 41-year-old male hemophilia B patient using a reverse sural artery flap operation. The patient presented with mild hemophilia, having $27 \%$ of the normal value of coagulation factor IX. Coagulation and the changing value of the coagulation factor were regularly measured, and $70 \%$ of the normal value of coagulation factor IX was maintained through the injection of recombinant coagulation factors and antihemorrhagics. Hematoma developed twice (postoperative day [POD] 5 and POD 7) and in each case the hematoma was removed. Injections of recombinant coagulation factors and antihemorrhagics were continuously administered until postoperative week 2 . When the coagulation factors were within normal ranges. In this article, a hemophilia $B$ patient underwent reverse sural artery flap surgery and the healing progress was analyzed. We conclude that higher than baseline levels of coagulation factors are needed for successful healing in reverse sural artery flap surgery.

Keywords Hemophilia B / Heel / Surgical flaps / Blood coagulation disorders / Factor IX

\author{
Correspondence: Jeong Su Shim \\ Department of Plastic and \\ Reconstructive Surgery, Catholic \\ University of Daegu School of Medicine, \\ 33 Duryugongwon-ro 17-gil, Nam-gu, \\ Daegu 705-718, Korea \\ Tel: $+82-53-650-4578$ \\ Fax: +82-53-650-4584 \\ E-mail:21csue@hanmail.net
}

Received: 24 Oct 2011 • Revised: 31 Jan 2012 • Accepted: 5 Feb 2012

pISSN: 2234-6163 • elSSN: 2234-6171 • http://dx.doi.org/10.5999/aps.2012.39.2.150 • Arch Plast Surg 2012;39:150-153

\section{INTRODUCTION}

Hemophilia is a genetic blood coagulation defect disease that is caused by a lack or deficit of blood coagulation factors in the plasma. The hemorrhagic tendency caused by abnormal blood coagulation factors has considerably limited the surgical procedures that can be performed on hemophiliacs.

If the hemorrhagic tendency is not controled properly, problems may arise due to hemorrhage and hematoma during a flap operation. These problems may lead to necrosis of the flap, rupture of the wound, or delayed healing, and the donor area may be affected by complications caused by hemorrhage.

In this study, we performed a heel reconstruction on a pa- tient who had been diagnosed as a hemophiliac by performing a reverse sural artery flap operation. In particular, guidelines for pedicled flap surgery in hemophilia B patients have still not been defined. We report on the healing process accompanied by a review of the relevant literature.

\section{CASE}

A 41-year-old male patient, weighing $72.2 \mathrm{~kg}$ and measuring $168 \mathrm{~cm}$ tall, visited the hospital with his main complaint being a fracture of the right calcaneus and an L4 radius compression fracture that he had received after falling from a $7 \mathrm{~m}$ bridge. On the initial visit, the patient underwent catagmatic surgery for the 
open fracture. Slow wound recovery was observed because of a considerable volume of exudate and a hemorrhagic tendency. The coagulation-hemostasis test showed that the prothrombin time (PT) was 14.0 seconds, which was within the normal range ( 11.5 to 15 seconds), and the activated partial thromboplastin time (aPTT) was 180 seconds, which was longer than the normal range ( 28 to 45 seconds). The coagulation factor test performed in the Department of Hematology and Medical Oncology showed that the activity of coagulation factor IX in the patient's blood was as low as $27 \%$; therefore, the patient was diagnosed with hemophilia B. The wound management was performed by continuing to use a coagulation-hemostasis test, regular injections of vitamin $\mathrm{K}$ to enhance coagulation factor synthesis, proper wound disinfection, and antibiotics. The patient was preoperatively injected with recombinant coagulation factor IX (Wyeth Inc., Seoul, Korea; $40 \mathrm{IU} / \mathrm{kg}$ IV) one day before the operation. One hour before the operation, an injection with the same amount of recombinant coagulation factor IX was administered. Botropase (Hemocoagulase $1 \mathrm{~N} 1 \mathrm{HU}$ ), a hemostatic, tranexamic acid, and vitamin $\mathrm{K}$ were also intraoperatively injected. Because one IU of coagulation factor IX per $1 \mathrm{~kg}$ of body weight can increase the coagulation factor IX activity by $1 \%$, the required quantity of the coagulation factor IX was calculated as follows: Factor IX dose $(\mathrm{IU})=$ Desired factor activity $(\%) \times$ weight $(\mathrm{kg})$. Because of the wide dissection area, the dose given to the patient was calculated according to the medical guideline that states that the coagulation factor activity is increased by $50 \%$ to $80 \%$ before a major operation such as abdominal surgery, brain surgery, or orthopedic surgery [1].

Following general anesthesia, the patient was moved into a prone position. An open wound measuring $5 \times 4 \mathrm{~cm}$, a part of the calcaneus, and the Kirschner wire used on the initial visit to the hospital, were exposed. The expected incision line was drawn including the margin of the wound. After performing the debridement, the island flap was drawn at the lower-third of the leg to be fitted to the area from which the soft tissue had been removed $(6 \times 5 \mathrm{~cm})$. The vascular pedicle included $2-3 \mathrm{~cm}$ wide fasciae, the sural nerve, and the accompanying sural artery. The small saphenous vein was included to make the venous return easier. The length of the vascular pedicle was calculated by adding 1-2 $\mathrm{cm}$ to the length between the proximal boundary of the deleted region and the pivot of the flap. It was verified that the vascular pedicle was not compressed. No vasogenic hemorrhage at the arteriole or venule was observed during the operation.

Three vials of BeneFix ( 1 vial: $1,000 \mu / 10 \mathrm{~mL}$ ), a hemostatic, and vitamin $\mathrm{K}$ were injected together intraoperatively, on the day of the surgery, and continuously injected on the day after the surgery. Two days after the operation, the BeneFix (1 vial) bid was maintained. While the patient remained under followup care, the bloody exudate and hematoma had increased. Hemostasis and hematoma removal were performed on postoperative day (POD) 5 and again on POD 7. On POD 7 the dose of BeneFix was increased to 4 vials and the packed red blood cells of $3 \mathrm{pt}$ were administered. The bloody exudate was continu-

\section{Fig. 1. A 41-year-old male with an open wound on the right heel area}

(A) Preoperative view. (B) Postoperative day 4 view. Hemostasis and hematoma removal were performed twice, on the fifth and seventh postoperative days. Bloody exudate was continuously observed even after the second hematoma removal, but the quantity had decreased and hematoma was no longer observed. (C) Postoperative 1 year 8 month view. Ongoing hematologic tests showed results in the normal range, and the wound recovered without any particular complications.
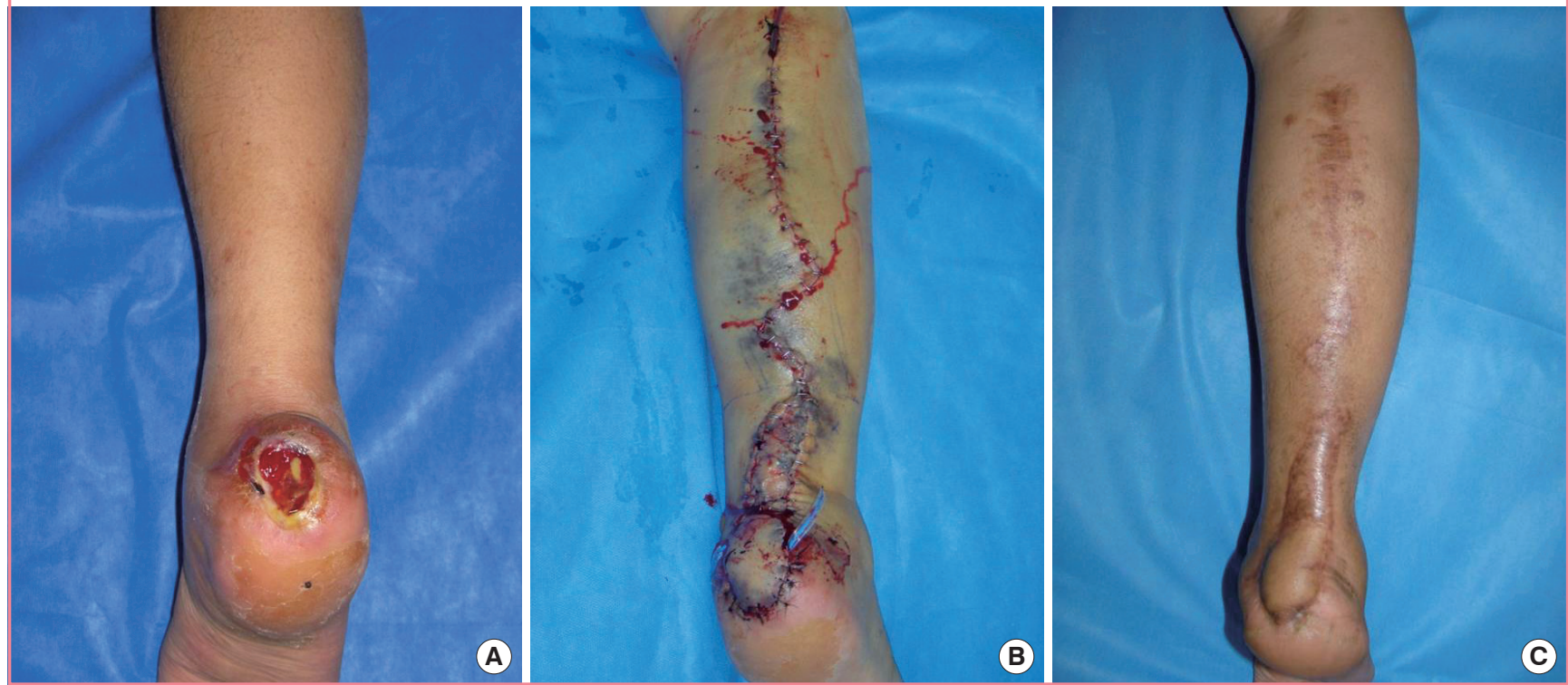
ously observed even after the second hematoma removal, but the quantity had decreased and the hematoma was no longer observed (Fig. 1). The BeneFix dose was maintained at 2 vials qd for one week, the catamnesis was observed, and a hemostatic and vitamin $\mathrm{K}$ were continuously injected. The recombinant coagulation factor IX was injected on the 17th day after the second hematoma removal operation. The follow-up coagulationhemostasis test showed that the normal range level had been maintained (Fig. 2). Thereafter, hematoma, hemorrhage, and other infections and complications were not found. Ongoing he-

\section{Fig. 2. Usage of recombinant coagulation factor $I X$ in the case}

Usage of recombinant coagulation factor IX (BeneFix, vials) in our case. We sustained a normal range of plasma concentration of aPTT depends on hemorrahgic condition. aPTT, activated partial thromboplastin time; POD, postoperative day.

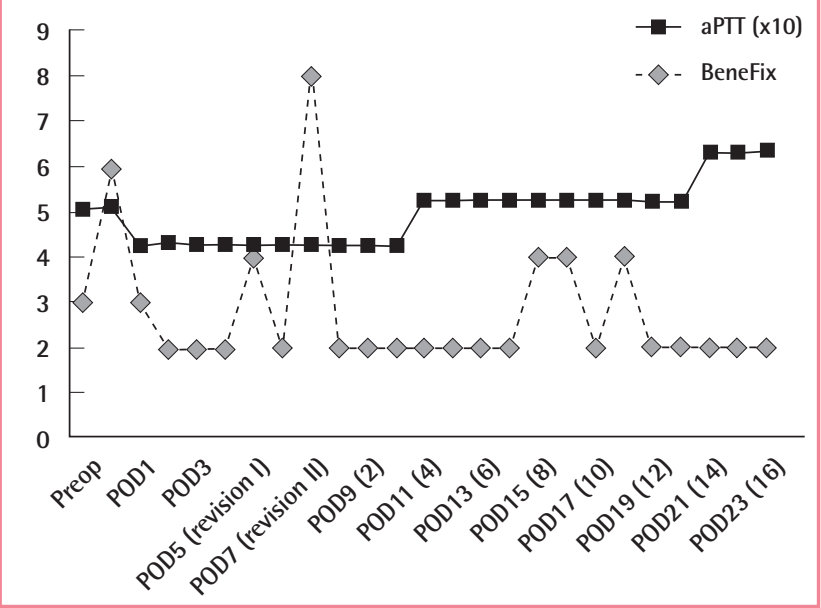

matologic tests showed that the results were in the normal range and the wound recovered without any specific complications.

\section{DISCUSSION}

Hemophilia B, which accounts for $20 \%$ of all hemophilia cases, is known as the second most frequent genetic disorder [2]. General medical guidelines have been established regarding the coagulation factor dose and administration interval, depending on the hemorrhagic region and degree, and the types of surgery performed when a hemorrhage occurs in a hemophiliac. In the preoperative management of a hemophilia $B$ patient, the severity of the disease should first be determined and the information about the treatment procedures undergone before the operation should be obtained from the family or the patient $[1,3]$. During diagnosis it is important to directly analyze the aPTT increase and the coagulation factor IX activity. Other coagulation factors also need to be tested and the circulatory antibodies must be analyzed in cases where blood or coagulation factor drugs have been injected continuously or repeatedly. Additionally, the prevention and treatment of other hemorrhagic tendencies are also important [1].

Hemorrhage in hemophiliacs may be acute. In addition, a hemorrhage may occur due to either trauma, or surgical or dental treatment. After the injection of the coagulation factors, the length of the half-life in the patient and whether the activity in the blood needs to be appropriately increased are examined. The coagulation activity is often tested preoperatively, intra-

Table 1. Therapeutic protocols for reconstructive surgery in hemophilia B patients

\begin{tabular}{|c|c|c|c|c|}
\hline & $\begin{array}{l}\text { Diagnosis \& operation } \\
\text { (age/weight) }\end{array}$ & Laboratory modality & $\begin{array}{l}\text { Preoperatively } \\
\text { medication }\end{array}$ & Postoperatively medication \\
\hline Knott et al. [5] & $\begin{array}{l}\text { Free latissimus dorsi } \\
\text { myocutaneous flap } \\
(65 /-\mathrm{kg})\end{array}$ & $\begin{array}{l}\text { Coagulation factor IX } \\
\text { 1. Until postoperative } 2 \mathrm{wk} \text { : } \\
\text { monitoring to keep 50\% higher } \\
\text { than normal value } \\
\text { 2. Postoperative } 3-4 \mathrm{wk} \text { : } \\
\text { keep } 10 \%-15 \%\end{array}$ & $\begin{array}{l}\text { Factor IX (BeneFix) } \\
\text { initial dose } \\
\text { 1. } 10,000 \text { unit qd } \\
\text { 2. 5,000 unit bid repeat }\end{array}$ & $\begin{array}{l}\text { Same dose for } 5 \text { postoperative } \\
\text { days } \\
\text { Combination with aspirin } \\
(325 \mathrm{mg}) \text { daily }\end{array}$ \\
\hline Lee et al. [7] & $\begin{array}{l}\text { Correction subtrochanteric } \\
\text { femur fracture }(22 / 65 \mathrm{~kg})\end{array}$ & $\begin{array}{l}\text { Coagulation factor IX } \\
\text { Basal value: } 20 \% \text {, keep to } 25-43 \%\end{array}$ & $\begin{array}{l}\text { Factor IX (Facnyne) } \\
\text { 1. } 750 \text { unit qd from } 11 \text { th } \\
\text { preoperative day to } \\
\text { 4th preoperative day } \\
\text { 2. 1,250 unit bid for } \\
3 \text { preoperative days }\end{array}$ & $\begin{array}{l}\text { 1. Operation day - 1st } \\
\text { postoperative day: } 1,250 \text { unit } \\
\text { bid } \\
\text { 2. } 2 \text { nd-3rd postoperative day: } \\
750 \text { unit } \\
\text { 3. } 4 \text { th-5th postoperative day: } \\
500 \text { unit }\end{array}$ \\
\hline Our case $e^{a, b)}$ & $\begin{array}{l}\text { Reverse sural artery flap } \\
(41 / 72.2 \mathrm{~kg})\end{array}$ & $\begin{array}{l}\text { Coagulation factor IX } \\
\text { Basal value: } 27 \% \text {, keep to } 50-80 \%\end{array}$ & $\begin{array}{l}\text { 1st preoperative day, } \\
\text { operation day: BeneFix } \\
3,000 \text { unit + Vik K bid }\end{array}$ & $\begin{array}{l}\text { 1. 2nd postoperative day- } 2 \text { wk: } \\
2,000 \text { unit qd } \\
\text { 2. } 5 \text { th-8th day: hematoma } \\
\text { removal- }>4,000 \text { unit bid }\end{array}$ \\
\hline \multicolumn{5}{|c|}{$\begin{array}{l}\text { a) For an adult, the mean increase of the circulatory factor IX activity on a pharmacokinetic test is } 0.8 \pm 0.2 \mathrm{IU} / \mathrm{dL}(\mathrm{range}, 0.3 \text { to } 1.4 \mathrm{IU} / \mathrm{dL}) \text { pe } \\
1 \mathrm{IU} / \mathrm{kg} \text { weight. Factor IX IU demand }(\mathrm{IU})=\text { weight }(\mathrm{kg}) \times \text { demanded factor IX increase }(\%) \times 1.2\left(\mathrm{IU} / \mathrm{dL} \text { per IU/kg); }{ }^{b} \text { For a child, the mean increas }\right. \\
\text { of the circulatory factor IX activity on a pharmacokinetic test is } 0.7 \pm 0.2 \mathrm{IU} / \mathrm{dL}(\text { range, } 0.3 \text { to } 1.1 \mathrm{IU} / \mathrm{dL}) \text { per } 1 \mathrm{IU} / \mathrm{kg} \text { weight. Factor IX IU demanc } \\
(\mathrm{IU})=\text { weight }(\mathrm{kg}) \times \text { demanded factor IX increase }(\%) \times 1.4(\mathrm{IU} / \mathrm{dL} \text { per IU/kg). }\end{array}$} \\
\hline
\end{tabular}


operatively, and postoperatively. Lee et al. [1] the trough level immediately before the factor injection and the peak level after the factor injection are measured. The coagulation factor activity is increased to $50 \%$ to $80 \%$ before a major operation such as abdominal surgery, brain surgery, and orthopedic surgery, and the coagulation factor injection is continued for 10 to 12 days postoperatively.

Ozkan et al. [4] emphasized the need for preoperative and postoperative management to be specifically adapted for a hemophiliac for microvascular free flap surgery. This was justified because the dissected face is varied even during a microvascular operation on a non-hemophiliac patient, and above all, the operation is considered a major procedure in terms of the vascular state and operating range [4]. Knott et al. [5] stated that the coagulation factor should be monitored (Table 1). They reported that there is a need to perform concentrated monitoring of complications such as thrombus by coagulation factors, hemolysis, and the induction of coagulation factor-inhibiting factors. They also stated that the socioeconomic expense needed for coagulation factors and discussing the methods to reduce the expense should not be ignored [5]. Bae et al. [6] injected 65 units per 1 $\mathrm{kg}$ of weight on the day of a total knee joint replacement. They measured the blood concentration on the day of the operation and supplemented the factor so that the intraoperative blood concentration was at $100 \%$. The postoperative dose was regulated so that the blood concentration was higher than $90 \%$ for the two postoperative days and higher than $50 \%$ throughout the first postoperative week. Significant decreases in flexion contracture, loss of aching, and a decreased frequency of postoperative hemorrhage were accomplished [6].

In our study, during the treatment period, a total of 66 vials of coagulation factor IX were injected: the dose consisted of 3 vials on the preoperative day, 6 vials on the day of operation, 8 vials on the fifth and seventh postoperative days when the hematoma removal was performed, and 2 vials on each of all the other days during the treatment period. If catamnesis had been observed periodically in the coagulation factor concentration and the supplementation of the coagulation factor had been performed more positively, based on the observation of the first heel reconstruction using the reverse artery sural flap operation, the postoperative hematoma generation might have been reduced even more. There are currently many surgical methods for heel reconstruction due to the development of microvascular techniques in plastic and reconstructive surgery such as a free flap using a small perforator artery flap. However, due to our patient's history of schizophrenia and hemophilia, we had to perform the pedicled flap method using the sural artery because it is safer and easier to control the vascular component than the small perforator artery free flap.

Since many dissection plans are involved in heel reconstruction using a reverse artery sural flap operation and a wide range of the lower leg is involved in the surgery, it is necessary to supplement the coagulation factor with reference to the hemophilia coagulation factor supplementation guidelines for major operations [1]. Therefore, we believe that it might have been necessary to inject a greater dose of coagulation factor IX preoperatively, intraoperatively, and postoperatively than the dose that was actually injected in this case. We performed follow-up with the patient for 2 years, and there have not been significant problems in this patient such as flap necrosis, infection, or hematologic complications.

We performed reverse artery sural flap operation on a hemophilia B patient whose blood coagulation factor IX activity had fallen to the mild hemophilia level, investigated the preoperative hemorrhage tendency, and reviewed the healing process that involved preoperative and postoperative supplements of coagulation factors. We herein report the case of a successful heel reconstruction performed while recognizing and being prepared for various factors including the prevention of not only hemorrhage, hematoma, or infection, but also thrombopoiesis caused by hypercoagulation. We hope that our experience suggests some approaches for others who may encounter a hemophilic patient with the need for pedicled flap operation.

\section{REFERENCES}

1. Lee DN, Oh YJ, Kyung YS, et al. A case of repeated cesarean section on the patient who has a moderate hemophilia B. Korean J Obstet Gynecol 2003;46:2317-22.

2. Jin KN, Lee W, Yin YH, et al. Preoperative evaluation of lower extremity arteries for free fibula transfer using MDCT angiography. J Comput Assist Tomogr 2007;31:820-5.

3. Kurachi K, Yao SN, Furukawa M, et al. Deficiencies in factors IX and VIII: what is now known. Hosp Pract (Off Ed) 1992;27:41-51.

4. Ozkan O, Chen HC, Mardini S, et al. Microvascular free tissue transfer in patients with hematological disorders. Plast Reconstr Surg 2006;118:936-44.

5. Knott PD, Khariwala SS, Minarchek J. Hemophilia B and free tissue transfer: medical and surgical management. Ann Plast Surg 2005;54:336-8.

6. Bae DK, Yim CM, Jeon MH, et al. TKA in hemophilic arthropathy of the knee.J Korean Orthop Assoc 1999;34:489-94.

7. Lee HJ, Jun JH, Kim KH, et al. Anesthetic management of a patient with hemophilia B. Korean J Anesthesiol 2004; 46:376-7. 